\title{
Terapia fotodinâmica na artrite experimental induzida por Paracoccidioides brasiliensis
}

\author{
Photodynamic therapy in experimental arthritis induced by Paracoccidioides brasiliensis
}

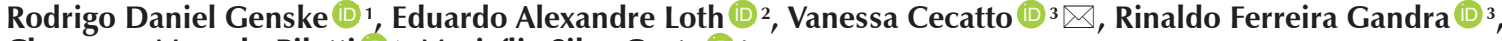 \\ Cleverson Marcelo Pilatti $\mathbb{B}^{1}$, Maricília Silva Costa $\mathbb{D}^{4}$ \\ - Engenharia Biomédica, Instituto de Pesquisa e Desenvolvimento da Universidade do Vale do Paraíba (UNIVAP). São José dos Campos, São Paulo, Brasil. \\ 2 Patologia, Laboratório Experimental de Microbiologia e Análises Clínicas, Ensino, Pesquisa e Extensão, Universidade Estadual do Oeste do Paraná (UNIOESTE). \\ Cascavel, Paraná, Brasil. \\ Ciências aplicadas à Saúde, Laboratório Experimental de Microbiologia e Análises Clínicas, Ensino, Pesquisa e Extensão, Universidade Estadual do Oeste \\ do Paraná (UNIOESTE). Cascavel, Paraná, Brasil. \\ ${ }^{4}$ Química Biológica, Instituto de Pesquisa e Desenvolvimento da Universidade do Vale do Paraíba (UNIVAP). São José dos Campos, São Paulo, Brasil.
}

Como citar este artigo (How to cite this article):

Genske, RD, Loth EA, Cecatto V, Gandra RF, Pilatti CM, Costa MS. Terapia fotodinâmica na artrite experimental induzida por Paracoccidioides brasiliensis (Photodynamic therapy in experimental arthritis induced by Paracoccidioides brasiliensis). Sci Med. 2019;29(9):ID32705. https://doi.org/10.15448/1980-6108.2019.2.32705

\section{RESUMO}

OBJETIVOS: Avaliar a eficácia da terapia fotodinâmica com Brilliant Blue $G$ no tratamento de um modelo experimental de artrite por Paracoccidioides brasiliensis (P. brasiliensis).

MÉTODOS: Após a indução de artrite experimental com isolado de $P$. brasiliensis da linhagem Pb18 nos joelhos de ratos Wistar, os animais foram divididos em grupos e submetidos a terapia fotodinâmica com fotossensibilizador Brilliant Blue $G$ intra-articular e a laserterapia apenas, sem o Brilliant Blue $G$. Todos os grupos receberam seus respectivos tratamentos do sétimo ao $11^{\circ}$ dia. Para análise do edema foi mensurado o diâmetro latero-lateral do joelho de cada animal diariamente e após o período de tratamento os animais foram sacrificados para dissecação do joelho experimental e coleta de sangue para análise por ELISA, a fim de quantificar os níveis de anticorpos anti-P. brasiliensis.

RESULTADOS: A aplicação da terapia fotodinâmica foi capaz de impedir a formação de edema quando comparado ao controle (p>0,005), bem como a produção de anticorpos anti-Gp-43 de P. brasiliensis $(\mathrm{p}=0,001)$. No exame anatomopatológico foi possível observar maior grau de sinovite e maior presença de granulomas com o fungo em seu interior no grupo que não recebeu tratamento quando comparado aos grupos que receberam a terapia fotodinâmica.

CONCLUSÕES: A terapia fotodinâmica foi eficaz para atenuar a artrite experimental induzida por $P$. brasiliensis no modelo articular proposto. DESCRITORES: paracoccidioidomicose; artrite experimental; terapia a laser; receptores purinérgicos; Brilliant Blue G.

\section{ABSTRACT}

AIMS: To evaluate the effectiveness of photodynamic therapy with Brilliant Blue $\mathrm{G}$ in the treatment of an experimental model of arthritis by Paracoccidioides brasiliensis (P. brasiliensis).

METHODS: After the induction of experimental arthritis with isolated from P. brasiliensis of lineage Pb18 in the knees of Wistar rats, the animals were divided into groups and submitted to photodynamic therapy with intra-articular Brilliant Blue G photosensitizer and laser therapy only, without Brilliant Blue G. All groups received their respective treatments from the seventh to the 11th day. For edema analysis, the knee lateral-lateral diameter of each animal was measured daily and after the treatment period the animals were sacrificed for experimental knee dissection and blood collection for analysis by ELISA, in order to quantify levels of anti-P. brasiliensis antibodies.

RESULTS: The results showed that the application of photodynamic therapy was able to prevent the formation of edema when compared to the control ( $\mathrm{p}>0.005)$, as well as the production of anti-Gp-43 antibodies from P. brasiliensis $(\mathrm{p}=0.001)$. In the anatomopathological examination it was possible to observe a higher degree of synovitis and a greater presence of granulomas with the fungus inside the group that did not receive treatment when compared to the groups that received the photodynamic therapy.

CONCLUSIONS: Photodynamic therapy was effective in attenuating the experimental arthritis induced by $P$. brasiliensis in the proposed joint model.

KEYWORDS: Paracocidioidomycosis; Arthritis experimental; laser therapy; Receptors purinergic; Brilliant Blue G. 
Abreviaturas: BBG, grupo Brilliant Blue G; ELISA, enzymelinked immunosorbent assay; GCA, grupo controle absoluto; GCN, grupo controle negativo; J, joules; PDT, terapia fotodinâmica; PDT 120J, grupo Terapia Fotodinâmica 120J; PDT 40J, grupo Terapia Fotodinâmica 40J.

\section{INTRODUÇÃO}

A Paracoccidioidomicose é uma micose sistêmica, causada pelo fungo dimórfico Paracoccidioides brasiliensis ( $P$. brasiliensis), considerada a micose sistêmica mais prevalente na América Latina, sendo que a maior casuística é encontrada no Brasil, com $80 \%$ dos casos [1]. Por se tratar de uma doença que a notificação não é compulsória, não existem dados precisos de incidência, estima-se que esta pode variar de 3 a 4 casos a cada um milhão, até 1 a 3 casos a cada 100 mil habitantes [2].

$\mathrm{Na}$ Paracoccidioidomicose, a infecção pelo patógeno ocorre pela inalação de conídios ou propágulos de $P$. brasiliensis, que se instalam nos pulmões. Posteriormente o fungo pode disseminar-se, causando lesões nos órgãos internos, mucocutâneas e osteoarticulares [3]. O quadro articular apresentase como sinovite aguda, frequentemente associado a quadro tóxico, febre, perda de peso, prostração podendo evoluir para a perda da função articular [4].

As infecções fúngicas geralmente apresentam várias problemáticas pertinentes ao tratamento, como efeitos colaterais severos, alto custo, longo tempo de tratamento, baixa adesão e recidivas da doença. $\mathrm{O}$ uso indiscriminado destas terapias promove a seleção natural de cepas microbianas resistentes e estão associadas a sequelas pós tratamento [5]. Entre as classes medicamentosas disponíveis atualmente para combater a paracoccidioidomicose estão as sulfonamidas, a anfotericina $\mathrm{B}$ e os derivados azólicos, como cetoconazol, fluconazol, itraconazol, voriconazol [6].

A terapia fotodinâmica (PDT), é uma forma de fototerapia baseada na utilização de substâncias fotossensibilizadoras nos tecidos biológicos e ativação destas pela presença da luz. As células-alvo são coradas com o fotossensibilizador e irradiadas com luz, conferindo o efeito fotoquímico que leva à morte celular [7]. A PDT apresenta vantagens em relação aos antimicrobianos usuais, como o baixo custo, propriedades cicatrizantes, ação local e minimamente invasiva, baixo risco de desenvolvimento de resistência microbiana e alta seletividade das células-alvo [8].
É sabido que purinas extracelulares, como a adenosina trifosfato, funcionam como sinalizadoras em processos fisiológicos através da ativação de receptores purinérgicos, como aqueles da família P2X [9]. Dentre os membros da família $\mathrm{P} 2 \mathrm{X}$ está o receptor $\mathrm{P} 2 \mathrm{X} 7$ (P2X7r). Ele é um importante receptor de membrana envolvido em diversos processos fisiopatológicos tais como a apoptose, necrose e a resposta inflamatória [10].

O P2X7r encontra-se em grande quantidade no coração, fígado, musculo esquelético, pâncreas e em monócitos, macrófagos e linfócitos humanos. Em camundongos o P2X7r também pode ser encontrado em células do sistema imune, tal qual acontece em humanos [10]. Por sua vez, o Brilliant Blue $G$, um corante alimentar, apresenta estrutura semelhante aos agonistas do $\mathrm{P} 2 \mathrm{X} 7 \mathrm{r}$, tornando-o um ideal bloqueador seletivo desse receptor $[11,12]$. Já foi observado na literatura efeitos como a redução da resposta inflamatória e a recuperação em lesões medulares em ratos que utilizaram o Brilliant Blue $G$ a fim de inibir o P2X7r [13, 14].

Em função das evidências apontadas pela literatura, demonstrando os efeitos benéficos da inibição do $\mathrm{P} 2 \mathrm{X} 7 \mathrm{r}$ em processos patogênicos, especialmente naqueles causados por potentes agentes biológicos [15], é necessário o estudo sobre os efeitos do uso da terapia fotodinâmica com Brilliant Blue $G$ no tratamento da artrite por P. brasiliensis. Assim, o objetivo desse estudo foi avaliar a eficácia da terapia fotodinâmica com Brilliant Blue $G$ no tratamento de um modelo experimental de artrite por $P$. brasiliensis.

\section{MÉTODOS}

Após aprovação pelo Comitê de Ética em Uso de Animais no 52/13 da Universidade Estadual do Oeste do Paraná, o estudo utilizou 42 ratos Wistar, machos, distribuídos em sete grupos. Os grupos Controle Absoluto (GCA), Controle Negativo (GCN) e Brilliant Blue $\mathrm{G}$ (BBG) serviram como controle do experimento. Os grupos Terapia Fotodinâmica 120J (PDT 120J), Terapia Fotodinâmica 40J (PDT 40J), Laser 120J e Laser 40J representaram os grupos tratados e foram comparados entre si e com os três grupos controle.

Os animais do GCA receberam infusão intra-articular de $50 \mu 1$ de solução salina tampão fosfatada estéril, no joelho direito da pata posterior e serviu como controle absoluto do estudo. Os animais dos demais grupos foram submetidos ao desenvolvimento experimental de artrite de acordo com modelo descrito por Loth et al. [16] que mimetiza a paracoccidioidomicose articular em humanos, através da injeção de $50 \mu 1$ de 
isolado de $P$. brasiliensis da linhagem Pb18 viáveis com concentração $10^{5}$. Todos os animais, previamente aos experimentos, foram anestesiados com $50 \mathrm{mg} / \mathrm{kg}$ de cetamina e $5 \mathrm{mg} / \mathrm{kg}$ de midazolan por via intraperitoneal.

A avaliação da formação de edema dos joelhos dos animais ocorreu diariamente durante o experimento. A primeira mensuração foi no início do experimento, imediatamente antes da indução do modelo experimental de artrite e a última medida ocorreu antes do sacrifício. Foi utilizado paquímetro analógico $\left(\right.$ Western $\left.^{\circledR}\right)$ e mensurado o diâmetro látero-lateral do joelho posterior direito de cada animal, em milímetros.

Conforme o modelo experimental utilizado aguardou-se sete dias para a indução da artrite. Nessa data, os grupos BBG, PDT 40J e PDT 120J receberam injeção intra-articular de $100 \mu 1$ de Brilliant Blue $G$ (Darmstadt, Alemanha) na dose de $45 \mathrm{mg} / \mathrm{kg}$. Em seguida, os dois últimos grupos foram tratados com laser na densidade de energia de $40 \mathrm{~J} / \mathrm{cm}^{2}$ e $120 \mathrm{~J} / \mathrm{cm}^{2}$, respectivamente. O laser utilizado foi GaAlAs $(660 \mathrm{~nm}$, $30 \mathrm{~mW}$ ), marca Ibramed ${ }^{\circledR}$, aplicado de forma pontual no joelho que recebeu o inóculo, do sétimo ao 11을.

Os grupos Laser $40 \mathrm{~J}$ e Laser $120 \mathrm{~J}$ recebem o tratamento com laser da mesma forma que os grupos PDT 40J e PDT 120J, porém sem a injeção de BBG intra-articular. Esses grupos foram utilizados para analisar o efeito isolado da irradiação, devido a sua ação em alguns microrganismos. $\mathrm{O}$ grupo $\mathrm{BBG}$, por sua vez, não teve intervenção com laser e serviu para verificar o efeito isolado do corante, devido às suas características bactericidas. Por fim, os grupos GCA e GCN, que não foram submetidos a nenhum protocolo de tratamento, somente a mensuração do edema. A mensuração do edema e aplicação do laser ocorreu todos os dias durante o experimento, sempre no mesmo horário, com os animais acordados.

Após o término do tempo de tratamento, todos os animais foram anestesiados com cetamina e xilazina por via intraperitoneal $(50 \mathrm{mg} / \mathrm{kg}$ peso animal) para punção cardíaca e coleta de sangue para análise de titulação de anticorpos anti-P. brasiliensis por ELISA (enzyme-linked immunosorbent assay) e procedimento cirúrgico para extração articulação infundida. As amostras de soro obtidas do sangue dos animais foram distribuídas em placas de 96 poços sensibilizadas com Gp 43ka de P. brasiliensis, para posterior leitura por absorbância a $492 \mathrm{~nm}$. Todos os ensaios foram realizados em triplicata.

O produto de dissecção da articulação do joelho direito da pata posterior de cada animal foi fixado em solução formalina a $10 \%$, descalcificada em ácido tricloroacético a $30 \%$, incluída em parafina, cortado longitudinalmente em micrótomo e coradas com o método de hematoxilina-eosina para evidenciar a formação de granulomas e pelo método de Grocott, para evidenciação do $P$. brasiliensis.

A avaliação da intensidade da artrite foi realizada utilizando a Escala da Artrite de Hansch et al. [17], atribuindo zero a três pontos para as variáveis avaliadas: hiperplasia do mesotélio da membrana sinovial, infiltrado celular no tecido sinovial, formação de pannus e destruição da cartilagem. Os sinais clássicos também foram quantificados pelo grau de intensidade em cruzes.

Para a análise estatística dos dados obtidos do teste de ELISA e mensuração do edema foi utilizada estatística inferencial por meio do teste de análise de variância, com nível de significância de 5\%. A análise qualitativa dos exames anatomopatológicos foi expressa por estatística descritiva simples através da apresentação de distribuição de frequência.

\section{RESULTADOS}

Foi possível observar discreto aumento do diâmetro lateral com formação de edema nos grupos tratados. No GCN houve diferença estatisticamente significante entre o início e o término do estudo, com aumento de $58,71 \%$ sobre o diâmetro inicial conforme demonstrado na Tabela 1. A titulação de anticorpos anti-P. brasiliensis apontou que houve menor produção de anticorpos específicos no grupo PDT 40J e maior produção de anticorpos específicos no grupo controle negativo $(\mathrm{p}=0,001)$. Nos demais grupos não foram verificadas diferenças estatisticamente significantes na comparação das médias dos grupos (Figura 1).

A análise qualitativa das biópsias das articulações revelou presença de inflamação granulomatosa tuberculoide na membrana sinovial de $100 \%$ dos animais do GCN, além de sinais típicos da paracoccidioidomicose articular na membrana sinovial, como presença de infiltrado inflamatório difuso, edema importante na região da inserção dos meniscos e granulomas epitelioides com diversos graus de maturidade, os quais continham células gigantes do tipo Langerhans com P. brasiliensis no seu interior, na forma de leveduras com múltiplos brotamentos. $\mathrm{Na}$ periferia dos granulomas, também foi possível observar leveduras com brotamentos, evidenciando sinovite, formação de pannus, localizada principalmente na região meniscal, com presença de necrose focal em algumas biopsias. Ainda na membrana sinovial 
nota-se proliferação de fibras colágenas e hiperplasia celular com formação de algumas camadas de células cúbica.

Tabela 1. Apresentação da média (em $\mathrm{mm}$ ) do diâmetro lateral dos joelhos dos ratos submetidos ao modelo experimental de paracoccidioidomicose articular*.

\begin{tabular}{lcccc}
\hline & $\begin{array}{c}\text { Pré- } \\
\text { inoculação }\end{array}$ & $\begin{array}{c}\text { Início do } \\
\text { tratamento }\end{array}$ & $\begin{array}{c}\text { Final do } \\
\text { tratamento }\end{array}$ & $\begin{array}{c}\text { Diferença } \\
(\%)\end{array}$ \\
\hline GCN & 9,59 & 10,73 & $15,22^{+}$ & 58,71 \\
Laser 40j & 10,3 & 11,3 & 10,56 & 2,52 \\
Laser 120j & 10,06 & 11,23 & 10,22 & 1,59 \\
BBG & 9,52 & 10,52 & 10,22 & 7,35 \\
PDT 40j & 10,15 & 10,76 & 10,34 & 1,87 \\
PDT 120j & 9,68 & 10,74 & 9,93 & 2,58 \\
GCA & 10,18 & 10,2 & 10,22 & 0,39 \\
\hline
\end{tabular}

* Mensurações realizadas da antes da inoculação de P. Brasiliensis nos joelhos dos ratos, no primeiro dia de tratamento e ao término do experimento.

+ Indica que houve diferença estatisticamente significante entre as médias do diâmetro lateral das articulações infundidas, das avaliações iniciais e finais dos grupos $(p>0,005)$. GCN - grupo Controle Negativo, submetidos ao modelo de artrite e sem intervenção; Laser 40J - submetidos ao modelo de artrite e tratados com laser com dose de 40 joules $/ \mathrm{cm}^{2}$; Laser $120 \mathrm{~J}$ - submetidos ao modelo de artrite e tratados com laser com dose de 120 joules $/ \mathrm{cm}^{2}$; BBG - submetidos ao modelo de artrite e tratados infusão articular de Brilliant Blue G; PDT 40J - Grupo terapia fotodinâmica, submetidos ao modelo de artrite, infusão articular de Brilliant Blue $G$ tratados com laser com dose de 40 joules $/ \mathrm{cm}^{2}$; PDT 120J - Grupo terapia fotodinâmica, submetidos ao modelo de artrite, infusão articular de Brilliant Blue G tratados com laser com dose de 120 joules $/ \mathrm{cm}^{2}$; GCA - grupo Controle Absoluto, não submetido ao modelo experimental de artrite ou infusão de Brilliant Blue $G$.
O Grupo PDT 120J apresentou discreto edema sinovial focal, abaixo do menisco, sem evidência de formação de granuloma. Através do método de Grocott, notou-se aglomerado com pequeno número de leveduras e discreta sinovite. Os demais grupos tratados apresentaram formação de granuloma imaturo, com reação inflamatória pronunciada, sobretudo no grupo Laser 40J, onde foi possível observar sinovite mais severa, com formação de pannus. O número de levedura de $P$. brasiliensis evidenciado pelo método de Grocott, foi abundante. As cartilagens articulares e estruturas ósseas demonstraram integridade em todos os grupos (Figura 2).

Os exames anatomopatológicos das biópsias articulares não demonstraram formação de granuloma nos grupos PDT. Nos grupos expostos somente ao laser observou-se achados patológicos mais discretos e menos numerosos (Tabela 2). Os achados histológicos nas biópsias articulares dos animais dos grupos experimentais estão representados na Figura 3, de acordo com a Escala da Artrite de Hansch et al. [17]. Por meio dessa escala, o índice de artrite obtido no GCN apontou artrite grau 1,75. Os grupos PDT 40J e BBG apresentaram escore médio de 1 ponto e o grupo PDT 120J apresentou escore médio de 0,5, limitando-se a atrite discreta.

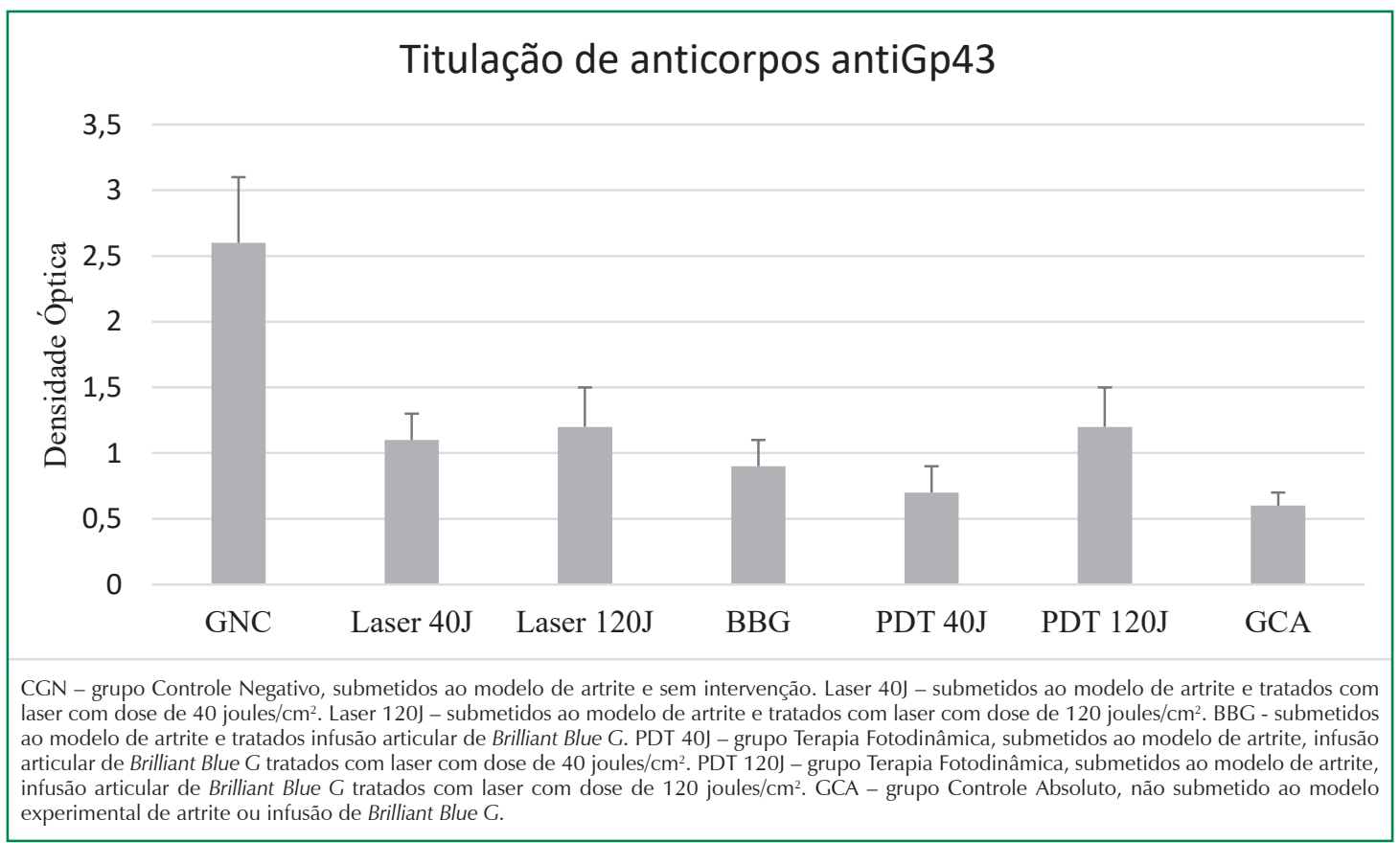

Figura 1. Apresentação da densidade óptica da titulação de anticorpos anti-Gp43 de P. brasiliensis. 


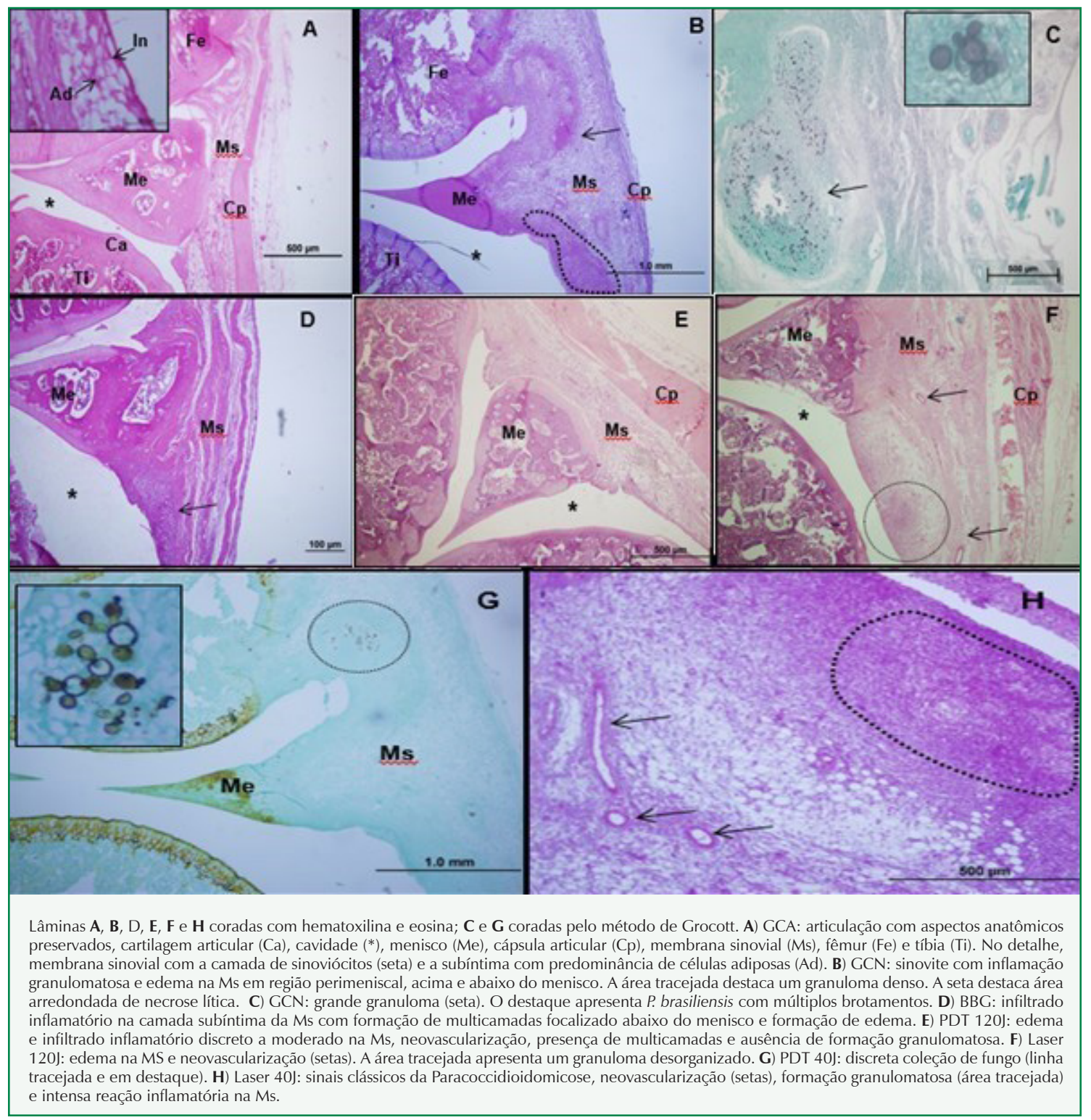

Figura 2. Fotomicrografias da articulação do joelho de ratos WISTAR, em corte sagital.

Tabela 2. Grau de intensidade em cruzes dos achados anatomopatológicos nos ratos dos grupos experimentais com paracoccidioidomicose articular

\begin{tabular}{|c|c|c|c|c|c|c|}
\hline Achados/Grupos & GCN & BBG & PDT 120J & Laser 120J & PDT 40J & Laser 40J \\
\hline Infiltrado Inflamatório & ++++ & ++ & + & ++ & ++ & ++ \\
\hline Edema Sinovial & ++++ & ++ & + & ++ & ++ & ++ \\
\hline Hiperplasia Sinovial & ++++ & ++ & + & ++ & ++ & ++ \\
\hline Granulomas Organizados & ++ & + & ausente & ausente & ausente & + \\
\hline Granulomas Frouxos & ++++ & + & ausente & ++ & ausente & ++ \\
\hline Paracoccidioides brasiliensis & ++++ & ++ & + & ++ & ++ & ++ \\
\hline Celulas Gigantes & ++++ & ++ & ausente & ++ & ++ & ++ \\
\hline Necrose Focal & + & ausente & ausente & ausente & Ausente & ausente \\
\hline Destruição de Cartilagem & ausente & ausente & ausente & ausente & Ausente & ausente \\
\hline Destruição Óssea & ausente & ausente & ausente & ausente & Ausente & ausente \\
\hline
\end{tabular}

GCN - grupo Controle Negativo, submetidos ao modelo de artrite e sem intervenção; BBG: grupo com infusão articular de Brilliant Blue G; PDT 120J - grupo Terapia Fotodinâmica

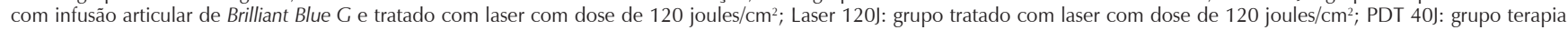

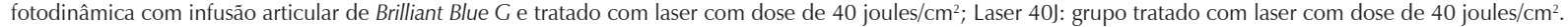




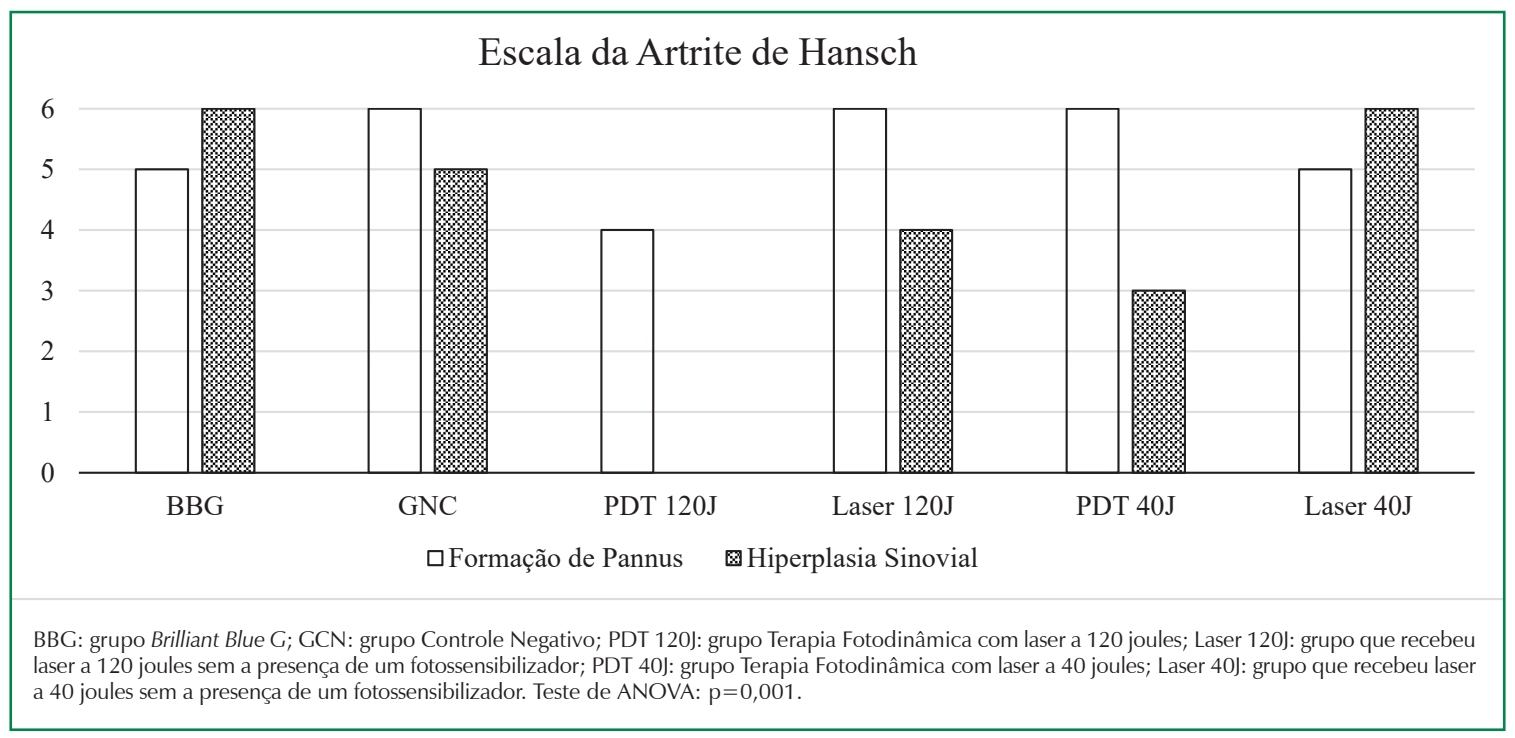

Figura 3. Achados histológicos nas biópsias articulares dos animais dos grupos experimentais de acordo com a escala da artrite de Hansch et al. [17].

\section{DISCUSSÃO}

Levando em consideração o potencial incapacitante da paracoccidioidomicose e as dificuldades enfrentadas em seu tratamento, a possibilidade de terapêuticas coadjuvantes torna-se de grande importância. Em oposição ao tratamento convencional, a PDT não produz resistência do patógeno e ainda pode ser utilizada para microrganismos que já adquiriram resistência medicamentosa [18]. Já existe relato de caso onde a PDT utilizada como coadjuvante na terapia com itraconazol, em lesões orais por P. brasiliensis, foi observado regressão das lesões e ausência de dor em apenas 4 dias após o início do tratamento com PDT [19].

Embora o primeiro caso de paracoccidioidomicose articular tenha sido relatado ainda em 1911 por Pereira e Viana, poucos estudos foram produzidos e encontrados na literatura científica, destes, a grande maioria descreve relatos de casos. Não obstante, menor número de publicações utilizando PDT como terapêutica contra paracoccidioidomicose foi encontrado. De modo que somos o primeiro grupo de pesquisa a utilizar essa modalidade de terapia contra paracoccidioidomicose articular, fato que dificultou uma discussão mais aprofundada sobre o tema.

No que tange a PDT usada contra a paracoccidioidomicose, alguns relatos de casos são descritos utilizando corantes fenotiazínicos como azul de metileno e azul de toluidina, além de porfirinas, como fotossensibilizadores [20]. No presente estudo, optamos por empregar o corante Brilliant Blue $G$ para essa função devido ao baixo custo e por ser inibidor específico do P2X7r [14].

A morte das células em necrose associada a danos tissulares liberam adenosina trifosfato no meio extracelular. Esse é reconhecido pelo P2X7r, que induz a produção de citocinas pró-inflamatórias e morte celular, o que pode aumentar a progressão de uma patologia com importante fator inflamatório [21]. Assim a utilização do Brilliant Blue $G$, como inibidor do P2X7r é capaz de minimizar os efeitos da necrose tecidual e limitar a progressão de patologias, como aconteceu no presente estudo, onde os grupos tratados com PDT, utilizando BBG como fotossensibilizador apresentaram sinais anatomopatológicos acentuados.

Em casos de tuberculose in vivo, causada por cepas agressivas, foi observado a inibição do P2X7 usando Brilliant Blue $G$ intraperitoneal, atenuando a doença, levando a ausência de necrose no pulmão, diminuição da formação granulomatosa e redução da morbimortalidade [15]. Resultados similares foram obtidos no nosso estudo, uma vez que no grupo PDT irradiado com 120 joules, os animais também apresentaram ausência de granulomas, processo inflamatório mais discreto e menor população de fungos na membrana sinovial. Nossos experimentos apontaram haver relação direta entre a dose de laser e a resposta obtida. Sendo que a terapia apenas com laser foi eficaz para controlar o edema, mantendo os 
sinais clássicos de sinovite nos joelhos dos animais irradiados com laser. Nos grupos Laser 40J e Laser $120 \mathrm{~J}$, foi possível notar a presença de granulomas, bem como o grupo BBG, eventos não presentes nos grupos PDT.

No presente estudo, o bloqueio do $\mathrm{P} 2 \mathrm{X} 7 \mathrm{r}$ pelo Brilliant Blue $G$ foi capaz de reduzir o perfil próinflamatório, com redução da formação de edema, número de granulomas e demais sinais anatomopatológicos clássicos da paracoccidioidomicose. Porém nos grupos tratados com terapia fotodinâmica, o bloqueio do receptor somado a possível produção de radicais livres, mostrou redução da reação inflamatória e controle do patógeno superior aos demais grupos.

Os mesmos autores que pesquisaram os casos de tuberculose com inibição do $\mathrm{P} 2 \mathrm{X} 7$ relataram ainda que encontraram níveis reduzidos de Interferon e Interleucinas $1 \mathrm{~b}$ e 10 e no sobrenadante de células de pulmonares de camundongos tratados com Brilliant Blue $G$ [15]. Outro estudo onde utilizaram um modelo de lesão espinhal em ratos, relataram redução da resposta inflamatória local após a administração de Brilliant Blue $G$ via intravenosa [14].

Em um modelo de artrite experimental em coelhos, induzida por coadjuvante de Freud suplementado com um liofilizado de Mycobacteria tuberculosis inativada pelo calor, usando benzoporfirina como fotossensibilizador, irradiaram $80 \mathrm{~J} / \mathrm{cm}^{2}$ de laser e mostraram prevenção de sinais clínicos da artrite, bem como diminuição dos leucócitos circulantes [22]. No presente estudo, investimos em experimentos com dose de laser mais elevada $\left(120 \mathrm{~J} / \mathrm{cm}^{2}\right)$ e obtivemos resultados positivos sobre o perfil inflamatório. Segundo alguns autores, a PDT deve ser utilizada em doses mais altas contra fungos, devido as estruturas da parede celular fúngica [23].

Além das análises anatomopatológicas, a avaliação do índice de artrite e edema, também demonstraram melhores resultados nos grupos PDT. A análise de titulação de anticorpos específicos anti-Gp43 de $P$. brasiliensis demonstrou níveis reduzidos desses anticorpos no grupo PDT, sendo que a quantidade desses anticorpos específicos IgG tem relação proporcional com a gravidade da paracoccidioidomicose [24].

Os dados do estudo, embora em curto tempo de tratamento realizado, apontam que a utilização do Brilliant Blue $G$ pode ser empregada na PDT e por sua vez usada como coadjuvante de drogas na paracoccidioidomicose articular, posto os benefícios já comprovados em diversos estudos e citados aqui, fato que deve encorajar o uso dessa metodologia em outros sítios periféricos de paracoccidioidomicose.

A partir do exposto até aqui, é possível concluir que a PDT foi útil para reduzir a intensidade da artrite experimental induzida no estudo. A melhor resposta obtida foi com a aplicação de $120 \mathrm{~J} / \mathrm{cm}^{2}$, na qual observou-se baixa titulação de anticorpos anti-Gp-43 de $P$. brasiliensis associada a menor formação de edema, menor índice de artrite e atenuação dos sinais anatomopatológicos da paracoccidioidomicose com ausência de granulomas.

\section{NOTAS}

Apoio financeiro

Este estudo não recebeu apoio financeiro de fontes externas.

Declaração de conflito de interesses

Os autores declaram não haver conflitos de interesses relevantes ao conteúdo deste estudo.

Contribuições dos autores

Todos os autores fizeram contribuições substanciais para concepção, ou delineamento, ou aquisição, ou análise ou interpretação de dados; e redação do trabalho ou revisão crítica; e aprovação final da versão para publicação.

Disponibilidade dos dados e responsabilidade pelos resultados

Todos os autores declaram ter tido total acesso aos dados obtidos e assumem completa responsabilidade pela integridade destes resultados.

\section{REFERÊNCIAS}

1. Lacaz, CS. Paracoccidioidomicose. In: Lacaz CS, Porto E, Martins JEC, Heins-Vaccari, EM, Takahashi de Melo, N, editores. Tratado de micologia médica. 9. ed. São Paulo: Sarvier; 2002. https://doi.org/10.1590/s003646652002000500013

2. Shikanai-Yasuda MA, Mendes RP, Colombo AL, Telles FQ, Kono A, Paniago AMM, Nathan A, Valle ACFD, Bagagli E, Benard G, Ferreira MS, Teixeira MM, Vergara MLS, Pereira RM, Cavalcante RS, Hahn R, Durlacher RR, Khoury Z, Camargo ZP, Moretti ML, Martinez R. Brazilian guidelines for the clinical management of paracoccidioidomycosis. Epidemiol Serv Saude. 2018;27(spe):e0500001. https://doi.org/10.1590/0037-86820230-2017 
3. Coutinho ZF, Silva D, Lazera M, Petri V, Oliveira RM, Sabroza PC, Wanke B. Paracoccidioidomycosis mortality in Brazil (1980-1995). Cad Saúde Pública. 2002;18(5):1441-54. https://doi.org/10.1590/s0102-311x2002000500037

4. Scheinberg MA, Cohen M, Abdalla RJ, Guidule J. Artroscopia na blastomicose articular do joelho: relato de um caso. Rev Bras Ortop. 1994;29(8):577-8.

5. Wanke B, Aide MA. Paracocidioidomycosis. J Bras Pneumol. 2009;35(12):1245-49.

6. Martinez R. Atualização no uso de agentes antifúngicos. J Bras Pneumol. 2006;32(5):449-60. https://doi. org/10.1590/s1806-37132006000500013

7. Prates RA, Silva EG, Suzuki LC, Paula CR, Ribeiro MS. Parâmetros de irradiação influenciam na inativação de leveduras tratadas com terapia fotodinâmica. Rev Bras Fis Med. 2010;4(1):53-7.

8. Issa MCA, Manela-Azulay M. Terapia fotodinâmica: revisão da literatura e documentação iconográfica. An Bras Dermatol. 2010;85(4):501-11. https://doi.org/10.1590/s0365-05962010000400011

9. Ralevic V, Burnstock G. Receptors for purines and pyrimidines. Pharmacol Rev. 1998;50(3):413-92.

10. Volonté C, Apolloni S, Skaper SD, Burnstock G. P2X7 receptors: channels, pores and more. CNS Neurol Disord Drug Targets. 2012;11(6):705-21. https://doi.org/10.2174/187152712803581137

11. Kagimoto HTS, Hisatomi T, Enaida H, Ishibashi T. Brilliant blue G for ILM staining and peeling. Retina Today. 2011:45-8.

12. Cankurtaran-Sayar S, Sayar K, Ugur M. P2X7 receptor activates multiple selective dye-permeation pathways in RAW 264.7 and human embryonic kidney 293 cells. Mol Pharmacol. 2009;76(6):1323-32. https://doi.org/10.1124/ mol.109.059923

13. Marcillo A, Frydel B, Bramlett HM, Dietrich WD. A reassessment of P2X7 receptor inhibition as a neuroprotective strategy in rat models of contusion injury. Exp Neurol. 2012;233(2):687-92. https://doi.org/10.1016/j. expneurol.2011.06.008

14. Peng W, Cotrina ML, Han X, Yu H, Bekar L, Blum L, Takano T, Tian GF, Goldman SA, Nedergaard M. Systemic administration of an antagonist of the ATP-sensitive receptor P2X7 improves recovery after spinal cord injury. Proc Natl Acad Sci U S A. 2009;106(30):12489-93. https://doi.org/10.1073/pnas.0902531106

15. Amaral EP, Ribeiro SC, Lanes VR, Almeida FM, de Andrade MR, Bomfim CC, Salles EM, Bortoluci KR, CoutinhoSilva R, Hirata MH, Alvarez JM, Lasunskaia EB, D’Império-Lima MR. Pulmonary infection with hypervirulent mycobacteria reveals a crucial role for the P2X7 receptor in aggressive forms of tuberculosis. PLoS Pathog. 2014;10(7):e1004188. https://doi.org/10.1371/journal.ppat.1004188

16. Loth EA, Biazin SK, Paula CR, Simão RC, de Franco MF, Puccia R, Gandra RF. Experimental model of arthritis induced by Paracoccidioides brasiliensis in rats. Mycopathologia. 2012;174(3):187-91. https://doi.org/10.1007/ s11046-012-9537-8

17. Hansch A, Frey O, Gajda M, Susanna G, Boettcher J, Bräuer R, Kaiser WA. Photodynamic treatment as a novel approach in the therapy of arthritic joints. Lasers Surg Med. 2008;40(4):265-72. https://doi.org/10.1002/1sm. 20620

18. Hamblin MR. Antimicrobial photodynamic inactivation: a bright newtechnique to kill resistant microbes. Curr Opin Microbiol. 2016;33:67-73. https://doi.org/10.1016/j.mib.2016.06.008

19. Ribeiro CM, Caixeta CA, Carli ML, Sperandio FF, Magalhães EMS, Pereira AAC, Hanemann JAC. Photodynamic inactivation of oral paracoccidioidomycosis affecting woman with systemic lupus erythematosus: an unusual case report. Photodiagnosis Photodyn Ther. 2017;17:160-3. https://doi.org/10.1016/j.pdpdt.2016.12.006

20. Sperandio FF, Simões A, Aranha AC, Corrêa L, Orsini Machado de Sousa SC. Photodynamic therapy mediated by methylene blue dye in wound healing. Photomed Laser Surg. 2010;28(5):581-7. https://doi.org/10.1089/ pho.2009.2601

21. Burnstock G, Krügel U, Abbracchio MP, Illes P. Purinergic signalling: from normal behaviour to pathological brain function. Prog Neurobiol. 2011;95(2):229-74. https://doi.org/10.1016/j.pneurobio.2011.08.006

22. Ratkay LG, Chowdhary RK, Neyndorff HC, Tonzetich J, Waterfield JD, Levy JG. Photodynamic therapy; a comparison with other immunomodulatory treatments of adjuvant-enhanced arthritis in MRL-lpr mice. Clin Exp Immunol. 1994;95(3):373-7. https://doi.org/10.1111/j.1365-2249.1994.tb07006.x 
23. Castano AP, Demidova TN, Hamblin MR. Mechanisms in photodynamic therapy: part one-photosensitizers, photochemistry and cellular localization. Photodiagnosis Photodyn Ther. 2004;1(4):279-93. https://doi.org/10.1016/ S1572-1000(05)00007-4

24. Cavassani KA, Tristao FS, Oliveira LL, Rocha FA, Vancim JO, Moreira AP, Campanelli AP, Panagio LA, Milanezi CM, Martinez R, Rossi MA, Silva JS. Cell-free antigens from Paracoccidioides brasiliensis drive IL-4 producton and increase the severity of paracoccidioidomycosis. PLoS One. 2011;6(6):e21423. https://doi.org/ 10.1371/journal.pone.0021423 